Article - Human and Animal Health

\title{
Molecular Detection of Medically Important Candida species from Droppings of Pigeons (Columbiformes) and Captive Birds (Passeriformes and Psittaciformes)
}

Isabelle Regina de Oliveira Queiroz-Aaltonen ${ }^{1}$

https://orcid.org/0000-0003-2900-2037

Marcílio Ferreira de Melo Neto ${ }^{2}$

https://orcid.org/0000-0002-9000-8772

Luísa Andrea Villanueva da Fonseca ${ }^{3}$

https://orcid.org/0000-0002-5715-636X

Denise Maria Wanderlei Silva ${ }^{2}$

https://orcid.org/0000-0001-9641-4264

\section{Fernanda Cristina Albuquerque Maranhão ${ }^{2^{*}}$}

https://orcid.org/0000-0002-4255-6563

${ }^{1}$ University of Turku, Aerobiology Sector, Turku, Finland; ${ }^{2}$ Universidade Federal de Alagoas, Institute of Biological and Health Sciences, Department of Microbiology, Maceió, Alagoas, Brazil; ${ }^{3}$ Universidade de São Paulo, Institute of Biomedical Sciences, São Paulo, São Paulo, Brazil.

Editor-in-Chief: Alexandre Rasi Aoki

Associate Editor: Camila Fediuk de Castro Guedes

Received: 2020.12.03; Accepted: 2021.07.21.

${ }^{*}$ Correspondence: fcam@icbs.ufal.br; Tel.: +55 (82) 3214-1065 (F.C.A.M).

\section{HIGHLIGHTS}

- All fecal samples from Columbia livia and captive birds were positive for yeast.

- A simple boiling method provides DNA to ensure success in specific amplifications.

- Pigeon feces held more potentially pathogenic Candida spp. compared to captive birds' stool.

- $80 \%$ of the samples isolated from birds' feces were Candida non-albicans.

- Cleaning urban spaces and captivity can provide fewer risks to individuals.

Abstract: Passeriformes and Psittaciformes birds and pigeons (Columba livia) are known to be reservoirs of microorganisms, and their stool allows fungi development. Since accumulated avian excreta can interfere with public health, this study aimed to perform a molecular screening of medically important Candida species in pigeon droppings in public places and birds raised in captivity. Excreta collected from captive birds (3 residences) and pigeons (4 districts) were inoculated on Sabouraud dextrose agar with chloramphenicol for Gram staining and subculture on Hicrome ${ }^{\circledR}$ Candida. Three DNA extraction methods were performed for 
comparison (commercial kit, in-house and by boiling) and PCR to screen 6 clinically important Candida species among the isolates. The correlation between phenotypic and molecular methods was calculated by kappa/K. Only 6 C. parapsilosis (20\%) were identified from captive birds' feces among 30 isolates $(80 \%$ not identified), while pigeons' feces harbored a greater diversity, with the 6 pathogenic species confirmed among 41 isolates: C. albicans $(31.70 \% / 13)$, C. krusei $(14.63 \% / 6)$, C. tropicalis $(14.63 \% / 6)$, C. parapsilosis $(17.10 \% / 7)$, C. glabrata $(14.63 \% / 6)$ and C. guilliermondii $(7.31 \% / 3) ; 100 \%$ correlation between tested methods $(K=1)$ for the first 3 species. Boiling DNA extraction method was fast and efficient to obtain viable DNA from Candida spp. for PCR. Our results indicate that pigeon droppings harbor more potentially pathogenic species than birds in residential captivity, which probably have non-albicans Candida less frequently isolated in infectious processes. The greater availability of nutrients may have contributed to a diversity of Candida spp. in feces from public environments.

Keywords: Avian excreta; Candida spp.; DNA extraction; PCR; captive birds.

\section{INTRODUCTION}

Psittaciformes and Passeriformes are the most common bird orders found captive in Brazil [1], while pigeons (Columba livia/Columbiformes) are considered as urban plagues among the synanthropic birds, acting as pathogenic agent disseminators [2]. Nitrogen is one of the avian excreta's components, and in great quantity, avian stool can promote the development of pathogenic fungi [3] and can even modify fungal communities in the soil [4]. Excreta accumulation is a risk of public health since there is the possibility of transmission of diseases through the inhalation of microorganisms [5].

The composition of the gastrointestinal microbiota of birds is quite varied and depends on the species, being also composed of fungi. Candida spp., Cryptococcus neoformans, Cryptococcus gatti and Trichosporon sp. were reported on the excreta of captive birds [6,7] and around 60 different pathogens have been detected on pigeons feces such as Cryptococcus sp., Candida spp., Trichosporon sp. and Rhodotorula sp. [8-11]. Despite of this, several birds such as specimens of Melopsittacus undulatus (Budgerigar; Psittaciformes), Paroaria dominicana (Red-cowled cardinal; Passeriformes), Amazona sp. (Amazon parrot; Psittaciformes) and pigeons (Columba livia; Columbiformes) can be susceptible of fungal diseases, for example, with symptoms that can affect the gastrointestinal tract and cause weakness [12-14].

Even though these birds pose a low risk to the health of the immunocompetent, immunocompromised individuals have a higher risk of acquiring mycosis from bird droppings in comparison to the general population [8]. Opportunistic fungal infections are expanding as individuals go under immunological or hematological disorders, medical treatments with long-term antibiotics, corticosteroids or immunosuppressive drugs, for example [15].

C. albicans and non-albicans Candida (NAC) can cause candidiasis with wide symptomatic variation, such as superficial mycosis or disseminated candidiasis, mainly affecting individuals with comorbidities and immunocompromised $[16,17]$. Although it is observed that $C$. albicans is more frequent and virulent, there has been an increase in the frequency of other species such as $C$. tropicalis, $C$; krusei, $C$. glabrata and $C$. parapsilosis [17-19].

Thus, the current study aims to detect potentially pathogenic yeasts (Candida species) from feces of pigeons' and captive birds in the city of Maceió, located in northeastern Brazil, comparing the frequencies observed in both avian groups, while also comparing the phenotypic and molecular methods for identification.

\section{MATERIAL AND METHODS}

\section{Sample collection, processing and phenotypic identification}

Excreta samples from birds of the species Melopsittacus undulatus (Psittaciformes), Amazona sp. (Psittaciformes) and Paroaria dominicana (Passeriformes) were collected from 3 residencies in different neighborhoods: Serraria (latitude: -9.602239; longitude: -35.723018), Barro Duro (latitude: -9.616528; longitude: -35.721437) and Petrópolis (latitude: -9.604141; longitude: -35.760321) in the city of Maceió (Alagoas, Brazil). Pigeons' feces (Columba livia, Columbiformes) were gathered in urban areas from 4 districts with intense flow of people: Downtown (latitude: -9.666677; longitude: -35.737206 ) and in the neighborhoods Prado (latitude: -9.668246; longitude: - 35.744972), Gruta de Lourdes (latitude: -9.621754; longitude: -35.731682) and Jatiúca (latitude: -9.650810; longitude: -35.708308).

Each species of captive bird was kept in their individual cages; therefore, the samples were individually labeled according to which avian species they were obtained from. Pigeon fecal dry samples were collected in public squares, all kept in individual sterile containers, for laboratory processing. 
Fecal samples $(1 \mathrm{~g})$ were macerated with a mortar, suspended in $25 \mathrm{~mL}$ of sterilized saline $(0.9 \%)$ with chloramphenicol $(0.05 \mathrm{~g} / \mathrm{L}$ ) (Sigma Aldrich), vortexed (5 min) and decanted (30 min). Subsequently, 100 $\mu \mathrm{L}$ of the supernatant were inoculated in triplicate on Sabouraud dextrose agar with chloramphenicol and plates were incubated at $30^{\circ} \mathrm{C}$ until $72 \mathrm{~h}$ [20], with daily inspections. Yeast colonies were assessed for Gram staining and cultivated on Hicrome ${ }^{\circledR}$ Candida differential agar (Himedia) $\left(30^{\circ} \mathrm{C} ; 48 \mathrm{~h}\right)$, followed by storage on Brain Heart Infusion (Sigma Aldrich) with glycerol (10\%) under $-20 \% \mathrm{C}$.

\section{DNA extraction and molecular identification}

Three different methods of DNA extraction were implemented in this study, in order to find a simple and

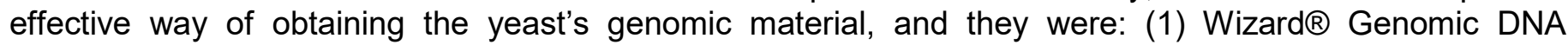
Purification Kit (Promega); (2) in-house described by Ferrer and coauthors [21] with phenol-chloroformisoamyl alcohol (25:24:1, vol/vol/vol); (3) and adapted from Mähnß and coauthors [22]: a single yeast colony was suspended in $100 \mu \mathrm{L}$ of sterile ultra-pure water and kept at $95^{\circ} \mathrm{C}$ (10 minutes) for cell lysis. After reaching room temperature, the microtubes were kept under $-20^{\circ} \mathrm{C}$ until the partial freezing of the debris, then centrifuged at $15.000 \mathrm{rpm}(11.340 \times \mathrm{g})$ for 5 minutes. $50 \mu \mathrm{l}$ of the supernatant containing genomic material was transferred to sterile microtubes for direct use or stored at $-20^{\circ} \mathrm{C}$ for following amplifications. Method (1) was applied on four isolates obtained from caged birds, whereas method (2) was used on 26 isolates, also from caged birds. Method (3) was used on all the isolates gathered from pigeons. The three methods were compared among each other through electrophoresis and polymerase chain reactions (PCRs).

In the PCR, the primers indicated in Table 1 were used for the amplification of ITS1-5.8S-28S and ITS2

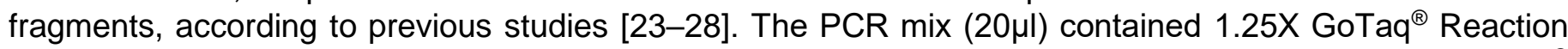

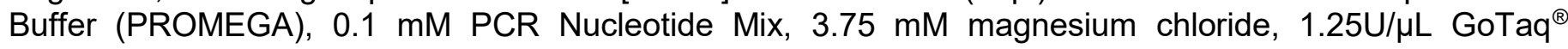
polymerase and $0.625 \mathrm{pmol}$ primers [12-14], with $1 \mu \mathrm{L}$ of DNA in a final volume per $20 \mu \mathrm{L}$. PCR conditions were: 5 minutes at $96^{\circ} \mathrm{C}$ for initial denaturation, followed by 40 cycles of $94^{\circ} \mathrm{C}$ for 30 seconds (denaturation), annealing at $58^{\circ} \mathrm{C}$ for 30 seconds, extension at $72^{\circ} \mathrm{C}$ for 30 seconds and a final step of $72^{\circ} \mathrm{C}$ for 15 minutes $[24,25]$.

Table 1. Oligonucleotide's primers used for the molecular identification of Candida species (Adapted from HSU and coauthors, $2003-[25])$.

\begin{tabular}{|c|c|c|c|c|}
\hline Target species & Primer & Sequence ( $5^{\prime}$ to $\left.3^{\prime}\right)$ & $\begin{array}{l}\text { Amplicon } \\
\text { size (pb) }\end{array}$ & $\begin{array}{c}\text { Genbank accession } \\
\text { number/Reference }\end{array}$ \\
\hline C. albicans & $\begin{array}{l}\text { CALB } 1 \\
\text { CALB } 2\end{array}$ & $\begin{array}{l}\text { TTTATCAACTTGTCACACCAGA } \\
\text { ATCCCGCCTTACCACTACCG }\end{array}$ & $\approx 273$ & $\begin{array}{l}\text { L47111 [26] } \\
\text { L28817 [27] }\end{array}$ \\
\hline C. krusei & $\begin{array}{l}\text { CKRU } 1 \\
\text { CKRU } 2\end{array}$ & $\begin{array}{l}\text { GCATCGATGAAGAACGCAGC } \\
\text { AAAAGTCTAGTTCGCTCGGGCC }\end{array}$ & $\approx 258$ & $\begin{array}{l}\text { AX592669 [28] } \\
{[23]}\end{array}$ \\
\hline C. parapsilosis & $\begin{array}{l}\text { CPA } 1 \\
\text { CPA } 2\end{array}$ & $\begin{array}{c}\text { GCCAGAGATTAAACTAACCA } \\
\text { CCTATCCATTAGTTTATACTCCGC }\end{array}$ & $\approx 300$ & $\begin{array}{l}\text { AF287909* } \\
\text { L47109 [26] }\end{array}$ \\
\hline C. tropicalis & $\begin{array}{l}\text { CTR } 1 \\
\text { CTR } 2\end{array}$ & $\begin{array}{l}\text { CAATCCTACCGCCAGAGGTTAT } \\
\text { TGGCCACTAGCAAAATAAGCGT }\end{array}$ & $\approx 357$ & $\begin{array}{l}\text { AF287910* } \\
\text { AF268095* }\end{array}$ \\
\hline C. guilliermondii & $\begin{array}{l}\text { CGU } 1 \\
\text { CGU } 2\end{array}$ & $\begin{array}{l}\text { GCATCGATGAAGAACGCAGC } \\
\text { GTTTGGTTGTTGTAAGGCCGGG }\end{array}$ & $\approx 315$ & $\begin{array}{l}\text { AX592669 [28] } \\
{[23]}\end{array}$ \\
\hline C. glabrata & $\begin{array}{l}\text { CGL } 1 \\
\text { CGL } 2\end{array}$ & $\begin{array}{c}\text { TTATCACACGACTCGACACT } \\
\text { CCCACATACTGATATGGCCTACAA }\end{array}$ & $\approx 423$ & $\begin{array}{l}\text { AB032177* } \\
\text { AF167993* }\end{array}$ \\
\hline
\end{tabular}

*Unpublished references

Amplicons were electrophoresed in an agarose gel (1\%) in Tris-acetate-EDTA (70v), stained with Nancy$450^{\circledR}$ (Sigma-Aldrich) and using a 100bp DNA Ladder (Promega). For validation of PCR reactions, reference strains of the American Type Culture Collection were used: C. albicans (ATCC 90028), C. tropicalis (ATCC 13803), C. krusei (ATCC 6258), C. parapsilosis (ATCC 22019) and C. glabrata (ATCC 90030).

\section{Map and Statistical analyses}

A map was generated through Qgis (v. 3.18) for indication of the neighborhoods from Maceió/AL: Barro duro (1), Petrópolis (2), Serraria (3), Gruta de Lourdes (4), Jatiúca (5), Downtown (6) and Prado (7). Descriptive analyses were made through JASP (v. 0.8.0.6) software, and Cohen's Kappa coefficient was 
applied to calculate the level of agreement between phenotypic (Hicrome ${ }^{\circledR}$ Candida differential agar) and molecular identification method (PCR). Sensitivity for Hicrome ${ }^{\circledR}$ Candida differential agar was calculated through the following equation:

$$
\text { Sensitivity } \frac{\text { (true positive) }}{\text { (true positive+false negative) }}
$$

\section{RESULTS}

The droppings' gathering sites were distributed in different neighborhoods of Maceió, northeastern Brazil (Alagoas). Among the captive birds, Amazona sp. was found in the Barro Duro (1), Paroaria dominicana in Petrópolis (2), Melopsittacus undulatus specimens in a house from Serraria (3), neighborhoods located in the central part of Maceió and characterized as residential areas, with a small flow of people around these birds. On Figure 1 it is possible to confirm the localization of each numbered collection point.

Pigeon's samples were collected in a bus station from Gruta de Lourdes (4), where kids played near to pigeons that were eating, and in the neighborhoods Jatiúca (5), Prado (7) and Downtown (6) (Figure 1), places with a high flow of people. The neighborhood Jatiúca has been a source of tourism value for Maceió, since it is close to the seashore, while Prado is a traditional neighborhood in the city, and its closeness to the city's Downtown also attracts many individuals.

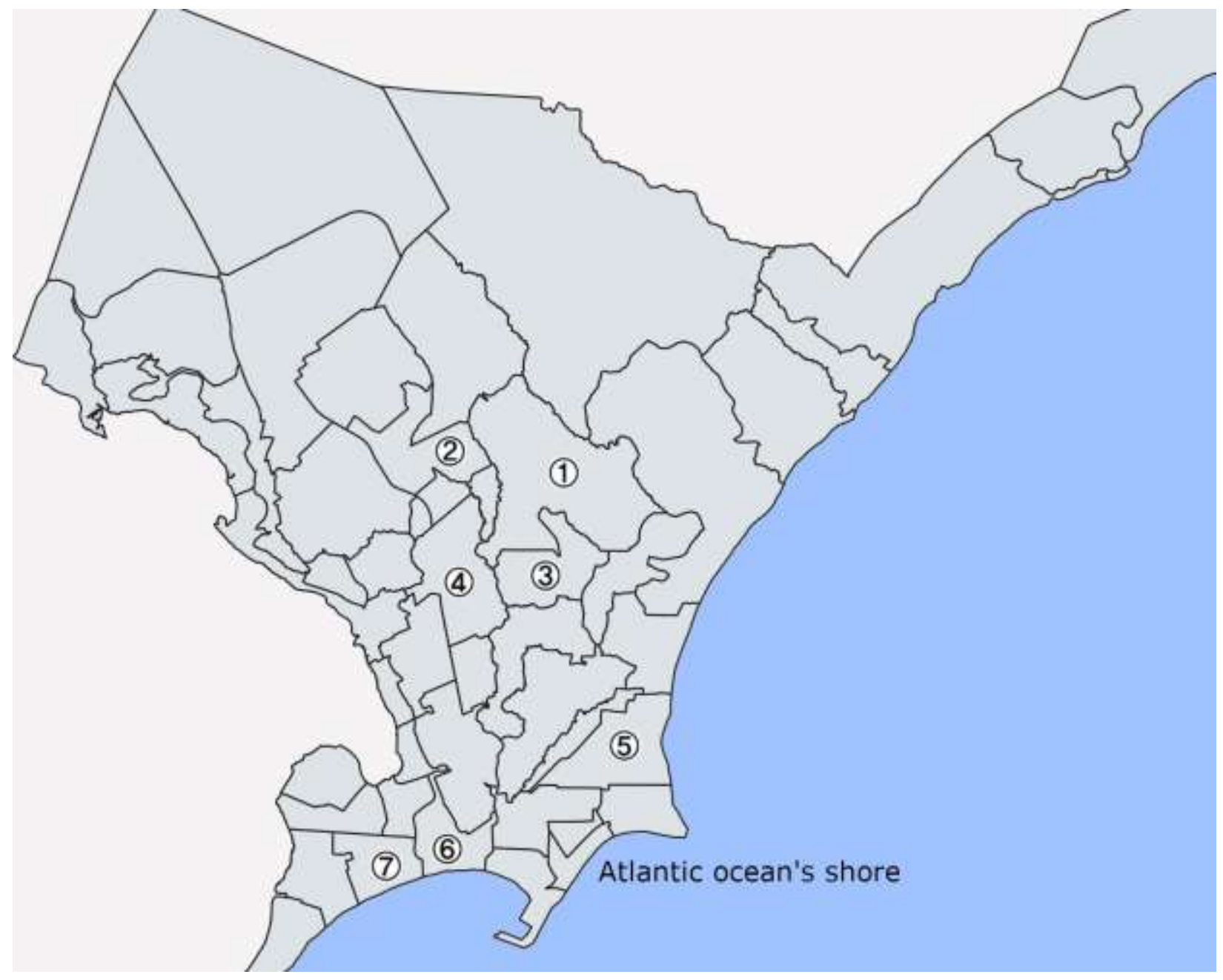

Figure 1. Partial map from the city of Maceió (Alagoas, Brazil) with localization of neighborhoods for sampling: Barro duro (1), Petrópolis (2), Serraria (3) for caged birds' stool sampling; Gruta de Lourdes (4), Jatiúca (5), Downtown (6) and Prado (7) for pigeon's samples.

After culturing (48h), all fecal samples from C. livia and birds held in captivity were positive for yeast growth. Through phenotypic methods (Gram stain and microscopy), we selected 71 strains with the morphology consistent with yeast, where $30(42.25 \%)$ of them came from captive poultry stool and 41 $(57.75 \%)$ were isolated from pigeons' excreta. We identified on the chromogenic medium three species of 
Candida from pigeon excreta: C. albicans (31.70\%; 13/41), C. tropicalis $(14.63 \%$; $6 / 41)$ and $C$. krusei, (14.63\%; 6/41), whereas 39.04\% were indicated as Candida sp., without specific color. All the isolates (30) from captive birds' feces remained as Candida sp. in chromogenic media.

As mentioned previously, we aimed to find a simple, fast, and low-cost method for obtained viable DNA for ITS-region amplification, and three distinct DNA extraction protocols were used in this study: (1) Wizard ${ }^{\circledR}$ Genomic kit, (2) in-house protocols with phenol-chloroform-isoamyl alcohol and (3) adapted from Mähnß et al. (2005). As expected, DNA extraction performed with Wizard ${ }^{\circledR}$ Genomic kit (1) and with phenol/chloroform (2) provided cleaner and higher quality DNA, while the method adapted from Mähnß and coauthors [22] carried out by high temperature followed by centrifugation provided genomic material of inferior quality, with impurities ("dirty"), but with sufficient quality to ensure accurate amplifications (PCR) for the identification of different Candida species.

Molecular identification by ITS-region (Fig. 2) confirmed C. albicans as the most frequent species among the pigeon excreta (31.70\%). Regarding non-albicans species (NAC), C. parapsilosis was isolated in $17.10 \%$, followed by $C$. krusei, $C$. tropicalis and $C$. glabrata with the same prevalence $(14.63 \%$, each), while $C$. guilliermondii was less observed in pigeon droppings (7.31\%).

From the samples isolated in captive birds' feces, $C$. parapsilosis was the only species identified, present in $20 \%(6 / 30)$ of the isolates. Thus, $80 \%$ of the samples $(24 / 30)$ could not be identified as any of the six species screened with specific primers. We used primers for the identification of six medically important species of Candida (C. albicans, C. tropicalis, C. glabrata, C. krusei, C. parapsilosis and C. guilliermondii); therefore, the remaining 24 strains were indicated as probable Candida non-albicans, not screened at this point. Total frequencies of Candida sp. isolated from the droppings of all avian species analyzed are shown on Table 2.

Table 2. Prevalence of Candida sp. isolates recovered from droppings of pigeons and captive birds in different locations in the city of Maceió, capital of Alagoas.

\begin{tabular}{|c|c|c|c|c|c|}
\hline \multirow[t]{2}{*}{ Fungal species } & \multicolumn{4}{|c|}{ Bird specimens } & \multirow{2}{*}{ Total } \\
\hline & $\begin{array}{c}\text { Melopsittacus } \\
\text { undulatus }\end{array}$ & $\begin{array}{c}\text { Paroaria } \\
\text { dominicana }\end{array}$ & Amazona sp. & $\begin{array}{c}\text { Pigeons } \\
\text { (Columba livia) }\end{array}$ & \\
\hline C. albicans & 0 & 0 & 0 & $13 / 41(31.70 \%)$ & 13 \\
\hline C. parapsilosis & 2 (6.67\%) & 0 & $4(13.33 \%)$ & $7 / 41(17.10 \%)$ & 13 \\
\hline C. krusei & 0 & 0 & 0 & $6 / 41(14.63 \%)$ & 6 \\
\hline C. tropicalis & 0 & 0 & 0 & 6/41 (14.63\%) & 6 \\
\hline C. glabrata & 0 & 0 & 0 & 6/41 (14.63\%) & 6 \\
\hline C. guilliermondii & 0 & 0 & 0 & $3 / 41$ (7.31\%) & 3 \\
\hline Candida sp. & 10 (33.33\%) & $3(10 \%)$ & $11(36.67 \%)$ & 0 & 24 \\
\hline Total & $12 / 30(40 \%)$ & $3 / 30(10 \%)$ & $15 / 30(50 \%)$ & $41(100 \%)$ & 71 \\
\hline
\end{tabular}

Species-specific PCR and conventional phenotypic method of species identification presented an interrater correlation for all $C$. albicans, $C$. krusei and $C$. tropicalis isolates (Kappa $=1$ ), when the sensitivity in species identification reached $100 \%$ (Table 3). The sensitivity of the Hicrome ${ }^{\circledR}$ Candida differential agar for the identification of $C$. glabrata, C. parapsilosis and C. guilliermondii was not calculated since the colonies can appear very similar on the chromogenic media. In Figure 2 it is possible to observe the specific amplicons for each species identified by the ITS region: $C$. guilliermondii (A), C. krusei (B), C. albicans (C, D), $C$. tropicalis (C), C. glabrata (D) and C. parapsilosis (E). All the isolates on Figure 2 were recovered from pigeon's stool, and the DNA extraction method used on them was adapted from Mähnß [22], confirming that even though providing us with lower quality DNA, this protocol is effective for carrying out PCR. 

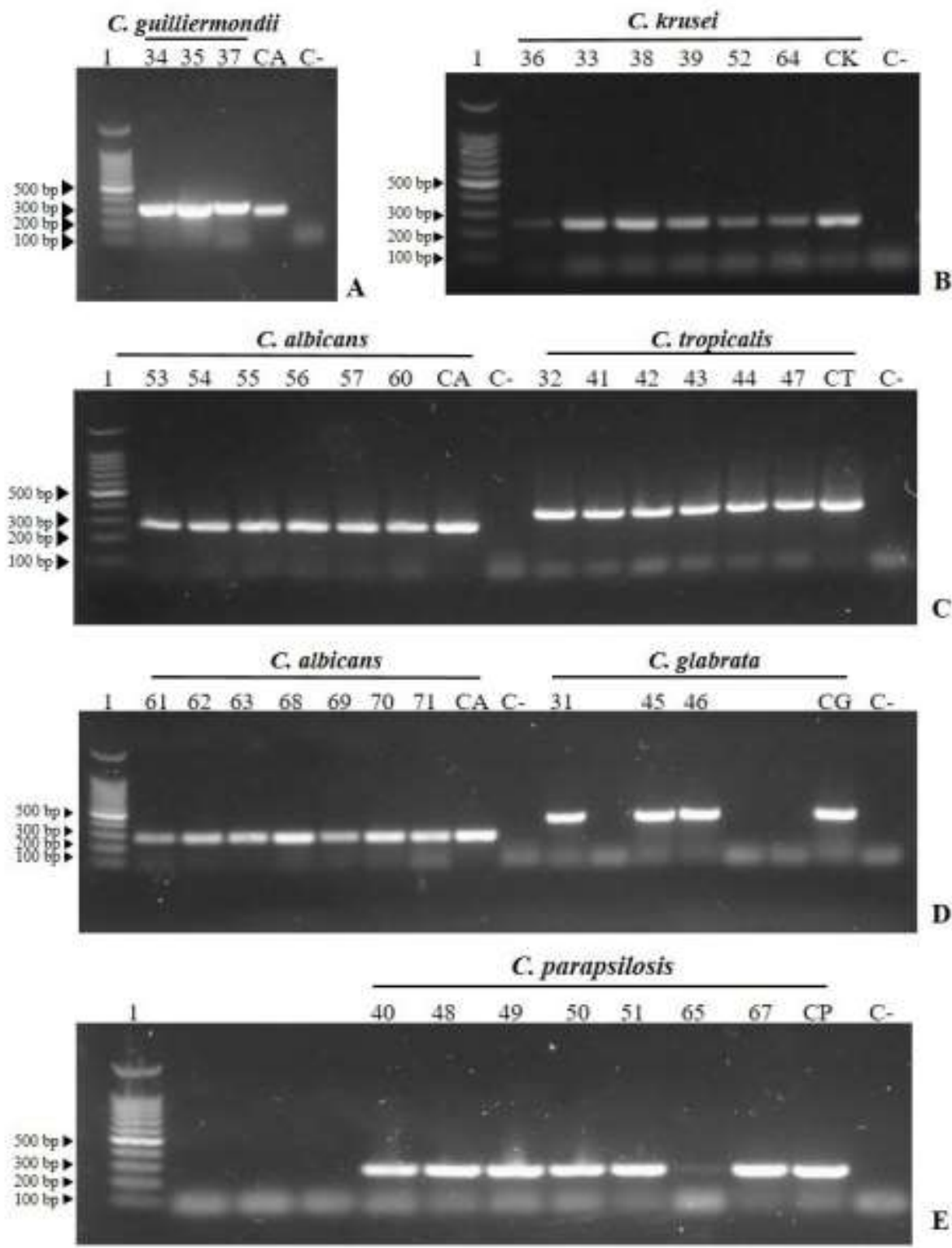

Figure 2. Different ITS-profiles for Candida species in agarose gel (1\%). 1: 100bp DNA Ladder; C-: Negative control; (A) C. guilliermondii ( $\approx 315 \mathrm{pb})$, CA: positive control of $C$. albicans was used for reaction validation, due to the absence of C. guilliermondii ATCC; (B) C. krusei ( $\approx 258 \mathrm{pb})$, CK: ATCC strain $\mathrm{n}^{\circ} 6258$ (positive control for C. krusel); (C) C. albicans ( $\approx 273 \mathrm{bp}$ ): from 53 to 60 , CA: ATCC strain $\mathrm{n}^{\circ} 90028$ (positive control for C. albicans); C. tropicalis ( $\approx 357 \mathrm{pb}$ ): from 32 to 47, CT: ATCC strain $n^{\circ} 13803$ (positive control for C. tropicalis); (D) Candida albicans ( $\left.\approx 273 \mathrm{pb}\right)$ : from 61 to 71, CA: ATCC strain n॰ 90028 (positive control for C. albicans); C. glabrata ( $\approx 423 \mathrm{pb})$ ): from 31 to 46, CG: strain $n^{\circ} 90030$ (positive control for C. glabrata); (E) Candida parapsilosis ( $\approx 300 \mathrm{pb})$, CP: strain $\mathrm{n}^{\circ} 22019$ (positive control for $C$. parapsilosis).

Table 3. Candida species obtained from droppings of pigeons and captive birds identified by phenotypic and molecular methods.

\begin{tabular}{lccc}
\hline \multicolumn{1}{c}{ Candida species } & $\begin{array}{c}\mathbf{N}^{\circ} \text { of species identified } \\
\text { Molecular } \\
\text { Phenotypic } \\
\text { identification }\end{array}$ & Sensitivity \\
\cline { 2 - 3 } C. albicans & 13 & 13 & $100 \%$ \\
C. krusei & 6 & 6 & $100 \%$ \\
C. tropicalis & 6 & 6 & $100 \%$ \\
C. parapsilosis $^{1}$ & 0 & 7 & - \\
C. glabrata $^{1}$ & 0 & 6 & - \\
C. guilliermondiit $^{\text {Not identified }}$ & 0 & 3 & - \\
\hline
\end{tabular}

${ }_{1}$ for these species (-), sensitivity tests have not been done since their morphologies on Hicrome ${ }^{\circledR}$ Candida differential agar can appear relatively similar. 


\section{DISCUSSION}

The incidence of the main Candida species of medical importance in avian feces was investigated in Maceió (Brazil), using phenotypic methods and PCR-ITS for identification and focusing on areas of great circulation of people and under domestic care. Despite Candida spp. being part of the microbiota of healthy humans, many species are involved in nosocomial bloodstream infections (BSI), invasive candidiasis (IC) cases and superficial mycoses in a wide variety of anatomical sites, and the acquisition can be endogenous or exogenous by environmental sources that facilitate contamination $[29,30]$.

Domestic and wild birds are carriers of human pathogenic fungi with zoonotic potential, as demonstrated by Cafarchia and co-workers (2006) after the isolation of Rhodotorula rubra, Cryptococcus albidus, Trichosporon cutaneum, C. albicans, C. guilliermondii and C. tropicalis [31]. The gastrointestinal microbiota of cockatoos (Nymphicus hollandicus) from pet shops, houses and breeders was evaluated in Fortaleza/CE (Brazil), identifying C. tropicalis and C. albicans (43.8\%; 6.6\%) [32], two species that were not detected in our captive birds droppings samples. In Pelotas/RS (Brazil), Mendes and coauthors [33] also observed species in Passeriformes' excreta that were sought with specific primers, but not confirmed in Maceió ( $C$. albicans $/ 31 \%$ and C. guilliermondii/ $4 \%$ ), also isolating C. famata (11\%), C. catenulata (4\%), C. intermedia $(2 \%)$, C. sphaerica (4\%), C. ciferri (6\%) and C. globosa (2\%), species that appear less frequently in clinical cases $[29,34]$.

Common species in infectious processes (C. albicans, C. krusei, C. tropicalis, C. glabrata and $C$. parapsilosis) have been detected in the feces of crow (Corvus sp., Passeriformes) in Malaysia [35], while in Maceió it was only possible to confirm C. parapsilosis in Passeriformes droppings. The difference is probably due to the fact that the avian species evaluated in Malaysia is considered synanthropic, whereas the animals we studied held in captivity. Simi and coauthors [7] evaluated birds of prey and the Psittacidae family with serious health problems, kept in public enclosures and quarantined, and found rarer Candida species in both groups (e. g., C. krusei, C. kefyr and C. famata), probably due to the impairment of the immune system. Since in our research only the 6 most frequent species of medical importance were screened, many strains of Candida spp. collected from feces of birds from the orders Passeriformes and Psittacidae did not have the species defined and may be rarer species.

In different points of Maceió, the presence of a wide variety of Candida species was found in pigeons feces, as well as in towers in Iran, where C. albicans, C. tropicalis, C. krusei, C. parapsilosis and C. guilliermondii were confirmed [36]. Medina and coauthors [37] detected pathogenic fungi on pigeons in the Canary Islands (Spain) from three different sources: droppings, cloaca and crop. Even though the presence of $C$. albicans and $C$. parapsilosis was also reported, $C$. guilliermondii was the most detected species in all the sites researched, and its frequency in excreta was even higher in comparison to the yeasts found in the cloaca and crop. These different patterns are probably due to climate, geographic and temporal conditions of each city, being $C$. guilliermondii the sixth most frequently isolated Candida species at hospitals in Latin America, and considered as an emerging pathogen $[38,39]$.

Considering that the avian cages in our study were cleaned daily and the pigeon excreta were old, and a greater diversity of potentially pathogenic Candida species was confirmed in the pigeon excreta compared to the fresh feces of birds in captivity, probably the cleaning actions interfered in the difference in abundance of Candida spp. Passeriformes' and Psittaciformes' excreta were not in contact with any organic substrate such as soil, which limits the contamination by diverse fungal species, while older excreta from pigeons were more exposed to the environment and consequently, to a great variety of fungi. Lee and coworkers (2017) stated that geographical, sociological and meteorological factors have a considerable role on the relative abundance of clinically relevant fungal species after evaluating pigeon stool in Seoul (South Korea). In addition, it is likely that many fungal species do not survive the passage through the gastrointestinal tract, and the transmission to the excreta happens more frequently through the air or soil [40].

At pigeon breeding farms in Beijing, China, Wu and coauthors [41] detected a low frequency of species such as C. glabrata (1/120), C. albicans (1/120) and C. catenulata (2/120), once the feces were fresh in a clean environment. The fact that there is no pigeon migration on breeding farms also interferes, as it avoids direct contact of these birds with fungal reproductive structures. Public places with organic matter available usually attract pigeons, and there are indications that the formation of fungal communities indoors (e.g., apartments) is influenced by the fungal composition of outdoors [42]; furthermore, fungi showed signs of dispersal limitation in hundreds of meters, indicating that there is a relation between the distance and dispersal decay in microbial communities. Therefore, many sources indicate that pigeon droppings in public places have a better chance of grouping a variety of fungi, as we have confirmed in different locations in Maceió, distributed from the central region of the city to near the coastal area. 
Environmental yeast strains can also show antifungal resistance and produce virulence factors, as demonstrated in $C$. albicans isolates resistant to itraconazole and fluconazole, or phospholipase-producing species [43,44]. Isolates of Candida spp. (41\%) collected from pigeon droppings around a university hospital showed the ability to adhere to the oral epithelium, in addition to the majority having varying abilities regarding the action of phospholipase and biofilm production, important virulence mechanisms for success in infection [45]. Even though $C$. albicans is still considered the most frequent species in fomites and infections, there has been an increase in the frequency of non-albicans Candida (NAC) in patients, asymptomatic carriers and in the environment, additionally, there is confirmation of Candida isolates showing intermediate susceptibility to azoles and echinocandin resistance [46,39]. As reported here, NAC have been identified in $45.83 \%$ of the isolates from Maceió, and according to Pfaller [47] C. albicans, C. parapsilosis, C. tropicalis, C. krusei and C. glabrata were responsible for more than $95 \%$ of community and hospital-acquired BSI cases in several countries, with a high incidence in North and Latin America [47].

In the Midwest region of Brazil, it was confirmed the incidence of $35.3 \%$ of $C$. albicans and $64.7 \%$ NAC, besides to indicate the emergence of non- $C$. albicans species azole-resistant [48], while in Alagoas more than 3,000 isolates of Candida spp. have been observed in different clinical samples for 8 years; then, it is clear that yeasts of the genus Candida continue to be the most involved in superficial and systemic mycoses $[30,47]$. Yapar $(2014)$ concluded that researchers worldwide pointed to a decrease of $65 \%$ to $44 \%$ in cases of IC by C. albicans between the late 1990 s and 2010, followed by an increase of cases assigned to $C$. tropicalis and $C$. parapsilosis. Therefore, since pigeons pose risks to animal and human health, the prevention of infections in immunosuppressed and immunocompetent individuals who live or work in environments with birds must be associated with a daily care, including cleaning and disinfecting urban and captivity spaces (washing and brushing with antimicrobial agents).

In addition to confirming the frequency of species, we also compared different methodologies for identifying Candida species, using a common chromogenic medium and gene-specific PCR. Chromogenic medium has been commonly used in clinical analysis laboratories for the identification of the main Candida species of medical interest, and the accuracy between this medium and the PCR was confirmed by a previous study, where Daef [50] tested the Hicrome ${ }^{\circledR}$ Candida medium in clinical isolates in Egypt and reported $100 \%$ sensitivity and $98.9 \%$ specificity for $C$. albicans and $100 \%$ for $C$. tropicalis and $C$. krusei when compared with semi-Nested PCR results. Our tests showed the same, and we indicated the positive correlation between the results observed in the chromogenic medium used with PCR for the species of $C$. albicans, $C$. tropicalis and C. krusei.

The choice to boil colonies for PCRs from the adapted method described by Mähnß and coauthors [22] provided us DNA with more impurities compared to the other protocols performed in this study (by kit and phenol-chloroform-isoamyl alcohol). However, despite its low quality, the DNA obtained was satisfactory, since our PCR-amplifications worked well. Junqueira and coauthors [51] and Ribeiro and coauthors [52] also adopted the same base-protocol for the molecular identification of clinical samples of Candida spp. and their PCR reactions were successful. This protocol is simple, fast, inexpensive, and efficient, being a good alternative for laboratories to use in PCR-based methods.

\section{CONCLUSION}

Based on our findings, pigeon droppings harbored more potentially pathogenic Candida species compared to the stool gathered from captive birds, indicating that in more exposed and older bird feces there will be a greater abundance of yeasts of Candida genus. This data demonstrates the need to monitor the presence of birds in places where there is a great circulation of people, since dispersed yeasts in their feces may act as opportunistic pathogens. Therefore, the appropriate maintenance of public areas and cages decreases the risks to individuals exposed to bird feces. In addition, we recommend an effective, simple and affordable methodology for identification of Candida species by PCR amplification of genomic DNA.

Conflicts of Interest: The authors declare no conflict of interest.

\section{REFERENCES}

1. Licarião MR, Bezerra DMM, Alves RRN. Wild birds as pets in Campina Grande, Paraíba State, Brazil: An Ethnozoological Approach. An Acad Bras Ciênc. 2013 Mar;85(1):201-13.

2. Cano-Terriza D, Guerra R, Lecollinet S, Cerdà-Cuéllar M, Cabezón O, Almería S, et al. Epidemiological survey of zoonotic pathogens in feral pigeons (Columba livia var. domestica) and sympatric zoo species in Southern Spain. Comp Immunol Microbiol Infect Dis. 2015 Dec;43:22-7. 
3. Lee IR, Morrow CA, Fraser JA. Nitrogen regulation of virulence in clinically prevalent fungal pathogens. FEMS Microbiol Lett. 2013 Aug 1;345(2):77-84.

4. Osono T, Hobara S, Fujiwara S, Koba K, Kameda K. Abundance, diversity, and species composition of fungal communities in a temperate forest affected by excreta of the Great Cormorant Phalacrocorax carbo. Soil Biol Biochem. 2002 Nov 1;34(11):1537-47.

5. Miskiewicz A, Kowalczyk P, Oraibi SM, Cybulska K, Misiewicz A. Bird feathers as potential sources of pathogenic microorganisms: a new look at old diseases. Antonie Van Leeuwenhoek. 2018 Sep 1;111(9):1493-507.

6. Marinho M, Táparo CV, Silva BG, Tencate LN, Perri SHV. Microbiota fúngica de Passeriformes de cativeiros da região noroeste do Estado de São Paulo [Microbiota from captive passeriformes of the northwest region of São Paulo]. Veterinária E Zootec. 2010;17(2):288-92.

7. Simi WB, Leite-Jr DP, Paula CR, Hoffmann-Santos HD, Takahara DT, Hahn RC. Yeasts and filamentous fungi in psittacidae and birds of prey droppings in midwest region of Brazil: a potential hazard to human health. Braz $\mathrm{J}$ Biol. 2019 Sep;79(3):414-22.

8. Haag-Wackernagel D, Moch H. Health hazards posed by feral pigeons. J Infect. 2004 May;48(4):307-13.

9. Costa AKF, Sidrim JJC, Cordeiro RA, Brilhante RSN, Monteiro AJ, Rocha MFG. Urban pigeons (Columba livia) as a potential source of pathogenic yeasts: a focus on antifungal susceptibility of Cryptococcus strains in Northeast Brazil. Mycopathologia. 2010 Mar;169(3):207-13.

10. Jang YH, Lee SJ, Lee JH, Chae HS, Kim SH, Choe NH. Prevalence of yeast-like fungi and evaluation of several virulence factors from feral pigeons in Seoul, Korea. Lett Appl Microbiol. 2011;52(4):367-71.

11. Glushakova, AM, Rodionova EN, Kachalkin AV. Yeasts in Feces of Pigeons (Columba livia) in the City of Moscow. Curr Microbiol. 2020;78(1):238-46.

12. Velasco MC. Candidiasis and cryptococcosis in birds. Semin Avian Exot Pet Med. 2000 Apr 1;9(2):75-81.

13. Sato Y, Aoyagi T, Kobayashi T, Inoue J. Occurrences of Candidiasis in a Fisher's Lovebird and a Budgerigar. J Vet Med Sci. 2001;63(8):939-41.

14. Donnelly KA, Wellehan JFX, Quesenberry K. Gastrointestinal Disease Associated with Non-albicans Candida Species in Six Birds. J Avian Med Surg. 2019 Dec;33(4):413-8.

15. Vázquez-González D, Perusquía-Ortiz AM, Hundeiker M, Bonifaz A. Opportunistic yeast infections: candidiasis, cryptococcosis, trichosporonosis and geotrichosis. JDDG J Dtsch Dermatol Ges. 2013;11(5):381-94.

16. Martin-Loeches I, Antonelli M, Cuenca-Estrella M, Dimopoulos G, Einav S, De Waele JJ, et al. ESICM/ESCMID task force on practical management of invasive candidiasis in critically ill patients. Intensive Care Med. 2019 Jun 1;45(6):789-805.

17. Maranhão F, Mendonça N, Teixeira T, Lages G, De Melo J, Porciuncula C, et al. Molecular Identification of Candida Species in the Oral Microbiota of Individuals with Down Syndrome: A Case-Control Study. Mycopathologia. 2020 May 26;185(3):537-43.

18. Brunetti G, Navazio AS, Giuliani A, Giordano A, Proli EM, Antonelli G, et al. Candida blood stream infections observed between 2011 and 2016 in a large Italian University Hospital: A time-based retrospective analysis on epidemiology, biofilm production, antifungal agents consumption and drug-susceptibility. Cortegiani $A$, editor. PLOS ONE. 2019 Nov 7;14(11):e0224678.

19. Singh DK, Tóth R, Gácser A. Mechanisms of Pathogenic Candida Species to Evade the Host Complement Attack. Front Cell Infect Microbiol. 2020;10(94).

20. Lazéra MS, Pires FD, Camillo-Coura L, Nishikawa MM, Bezerra CC, Trilles L, et al. Natural habitat of Cryptococcus neoformans var. neoformans in decaying wood forming hollows in living trees. J Med Vet Mycol Bi-Mon Publ Int Soc Hum Anim Mycol. 1996 Apr;34(2):127-31.

21. Ferrer C, Colom F, Frasés S, Mulet E, Abad JL, Alió JL. Detection and Identification of Fungal Pathogens by PCR and by ITS2 and 5.8S Ribosomal DNA Typing in Ocular Infections. J Clin Microbiol. 2001 Aug;39(8):2873-9.

22. Mähnß B, Stehr F, Schäfer W, Neuber K. Comparison of standard phenotypic assays with a PCR method to discriminate Candida albicans and C. dubliniensis. Mycoses. 2005 Jan;48(1):55-61.

23. Elie CM, Lott TJ, Reiss E, Morrison CJ. Rapid Identification of Candida Species with Species-Specific DNA Probes. J Clin Microbiol. 1998 Nov;36(11):3260-5.

24. Luo G, Mitchell TG. Rapid identification of pathogenic fungi directly from cultures by using multiplex PCR. J Clin Microbiol. 2002 Aug;40(8):2860-5.

25. Hsu M-C, Chen K-W, Lo H-J, Chen Y-C, Liao M-H, Lin Y-H, et al. Species identification of medically important fungi by use of real-time LightCycler PCR. J Med Microbiol. 2003 Dec;52(Pt 12):1071-6.

26. Williams DW, Wilson MJ, Lewis MAO, Potts AJC. Identification of Candida species in formalin fixed, paraffin wax embedded oral mucosa by sequencing of ribosomal DNA. Clin Mol Pathol. 1996 Feb;49(1):M23-8.

27. Srikantha T, Gutell RR, Morrow B, Soll DR. Partial nucleotide sequence of a single ribosomal RNA coding region and secondary structure of the large subunit 25 s rRNA of Candida albicans. Curr Genet. 1994 Oct;26(4):321-8. 
28. Barnett C, Beck J, Perry C. Detection of fungal pathogens using the polymerase chain reaction. US20030099946A1, 2003.

29. Raja NS. Epidemiology, risk factors, treatment and outcome of Candida bloodstream infections because of Candida albicans and Candida non-albicans in two district general hospitals in the United Kingdom. Int J Clin Pract. 2021;75(1):e13655.

30. De Albuquerque Maranhão FC, Oliveira-Júnior JB, dos Santos Araújo MA, Silva DMW. Mycoses in northeastern Brazil: epidemiology and prevalence of fungal species in 8 years of retrospective analysis in Alagoas. Braz $\mathrm{J}$ Microbiol. 2019 May 28;50(4):969-78.

31. Cafarchia C, Camarda A, Romito D, Campolo M, Quaglia NC, Tullio D, et al. Occurrence of yeasts in cloacae of migratory birds. Mycopathologia. 2006 Apr;161(4):229-34.

32. Brilhante RSN, Castelo-Branco DSCM, Soares GDP, Astete-Medrano DJ, Monteiro AJ, Cordeiro RA, et al. Characterization of the gastrointestinal yeast microbiota of cockatiels (Nymphicus hollandicus): a potential hazard to human health. J Med Microbiol. 2010 Jun 1;59(6):718-23.

33. Mendes JF, Albano APN, Coimbra MAA, de Ferreira GF, Gonçalves CL, Nascente P da S, et al. Fungi isolated from the excreta of wild birds in screening centers in Pelotas, RS, Brazil. Rev Inst Med Trop São Paulo. 2014;56(6):525-8.

34. Vieira JN, Feijó AM, Bueno ME, Gonçalves CL, Lund RG, Mendes JF, et al. Evaluation of the frequency of Candida spp. in hospitalized and non-hospitalized subjects. Braz J Biol. 2018 Nov;78(4):644-52.

35. Lord ATK, Mohandas K, Somanath S, Ambu S. Multidrug resistant yeasts in synanthropic wild birds. Ann Clin Microbiol Antimicrob. 2010 Mar 23;9:11.

36. Soltani M, Bayat M, Hashemi SJ, Zia M, Pestechian N. Isolation of Cryptococcus neoformans and other opportunistic fungi from pigeon droppings. J Res Med Sci Off J Isfahan Univ Med Sci. 2013 Jan;18(1):56-60.

37. Medina RI, Fuentes RL, Arteaga BM, Valcárcel RF, Arbelo AF, Padilla Del Castillo D, et al. Pigeons and their droppings as reservoirs of Candida and other zoonotic yeasts. Rev lberoam Micol. 2017 Dec;34(4):211-4.

38. Pfaller MA, Diekema DJ, Mendez M, Kibbler C, Erzsebet P, Chang S-C, et al. Candida guilliermondii, an Opportunistic Fungal Pathogen with Decreased Susceptibility to Fluconazole: Geographic and Temporal Trends from the ARTEMIS DISK Antifungal Surveillance Program. J Clin Microbiol. 2006 Oct;44(10):3551-6.

39. Da Matta DA, Souza ACR, Colombo AL. Revisiting Species Distribution and Antifungal Susceptibility of Candida Bloodstream Isolates from Latin American Medical Centers. J Fungi. 2017 May 17;3(2).

40. Lee WD, Fong JJ, Eimes JA, Lim YW. Diversity and abundance of human-pathogenic fungi associated with pigeon faeces in urban environments. Mol Ecol. 2017 Sep;26(17):4574-85.

41. Wu Y, Du P-C, Li W-G, Lu J-X. Identification and molecular analysis of pathogenic yeasts in droppings of domestic pigeons in Beijing, China. Mycopathologia. 2012 Sep;174(3):203-14.

42. Adams RI, Miletto M, Taylor JW, Bruns TD. Dispersal in microbes: fungi in indoor air are dominated by outdoor air and show dispersal limitation at short distances. ISME J. 2013 Jul;7(7):1262-73.

43. Sidrim JJC, Maia DCB de SC, Brilhante RSN, Soares GDP, Cordeiro RA, Monteiro AJ, et al. Candida species isolated from the gastrointestinal tract of cockatiels (Nymphicus hollandicus): In vitro antifungal susceptibility profile and phospholipase activity. Vet Microbiol. 2010 Oct 26;145(3-4):324-8.

44. Cafarchia C, Romito D, Coccioli C, Camarda A, Otranto D. Phospholipase activity of yeasts from wild birds and possible implications for human disease. Med Mycol. 2008;46:429-34.

45. Magalhães Pinto L, de Assis Bezerra Neto F, Araújo Paulo de Medeiros M, Zuza Alves DL, Maranhão Chaves G. Candida species isolated from pigeon (Columbia livia) droppings may express virulence factors and resistance to azoles. Vet Microbiol. 2019 Aug 1;235:43-52.

46. Storti LR, Pasquale G, Scomparim R, Galastri AL, Alterthum F, Gambale W, et al. Candida spp. isolated from inpatients, the environment, and health practitioners in the pediatric unit at the Universitary Hospital of the Jundiaí Medical College, state of São Paulo, Brazil. Rev Soc Bras Med Trop. 2012 Apr;45(2):225-31.

47. Pfaller MA, Moet GJ, Messer SA, Jones RN, Castanheira M. Candida Bloodstream Infections: Comparison of Species Distributions and Antifungal Resistance Patterns in Community-Onset and Nosocomial Isolates in the SENTRY Antimicrobial Surveillance Program, 2008-2009. Antimicrob Agents Chemother. 2011 Feb;55(2):561-6.

48. Mattos K, Rodrigues LC, Oliveira KMP de, Diniz PF, Marques LI, Araujo AA, et al. Variability in the clinical distributions of Candida species and the emergence of azole-resistant non-Candida albicans species in public hospitals in the Midwest region of Brazil. Rev Soc Bras Med Trop. 2017 Dec;50(6):843-7.

49. Yapar N. Epidemiology and risk factors for invasive candidiasis. Ther Clin Risk Manag. 2014 Feb 13;10:95-105.

50. Daef E, Moharram A, Eldin SS, Elsherbiny N, Mohammed M. Evaluation of chromogenic media and seminested PCR in the identification of Candida species. Braz J Microbiol. 2014;45(1):255-62. 
51. Junqueira JC, Fuchs BB, Muhammed M, Coleman JJ, Suleiman JMAH, Vilela SFG, et al. Oral Candida albicans isolates from HIV-positive individuals have similar in vitro biofilm-forming ability and pathogenicity as invasive Candida isolates. BMC Microbiol. 2011 Nov 4;11:247.

52. Ribeiro PM, Querido SMR, Back-Brito GN, Mota AJ, Koga-Ito CY, Jorge AOC. Research on Candida dubliniensis in a Brazilian yeast collection obtained from cardiac transplant, tuberculosis, and HIV-positive patients, and evaluation of phenotypic tests using agar screening methods. Diagn Microbiol Infect Dis. 2011 Sep;71(1):81-6.

(C) (1) 2021 by the authors. Submitted for possible open access publication under the terms and
conditions of the Creative Commons Attribution (CC BY NC) license
(https://creativecommons.org/licenses/by-nc/4.0/).

